\title{
Simulação de dados para avaliação genética de rebanhos de gado de corte
}

[Genetic evaluation of beef cattle herds through simulated data]

\author{
E.E. Cunha ${ }^{1,4}$, R.F. Euclydes ${ }^{2}$, R.A. Torres ${ }^{2}$, P.L.S. Carneiro ${ }^{3}$ \\ ${ }^{1}$ Aluna de pós-graduação - Departamento de Zootecnia - UFV \\ Av. P.H. Rolfs, $\mathrm{s} / \mathrm{n}$ \\ 36571-000 - Viçosa, MG \\ ${ }^{2}$ Departamento de Zootecnia - UFV - Viçosa, MG \\ ${ }^{3}$ Centro de Ciências Biológicas - UESB - Jequié, BA \\ ${ }^{4}$ Bolsista do $\mathrm{CNPq}$
}

\begin{abstract}
RESUMO
Utilizou-se o programa GENESYS para simular rebanhos de gado de corte selecionados, durante cinco gerações, por meio da seleção individual ou seleção com base no melhor preditor linear não-viesado (BLUP). Foram comparados os valores fenotípicos médios e a endogamia média, resultantes da aplicação desses métodos. A característica quantitativa simulada foi o ganho de peso diário, com fenótipo médio inicial de $1 \mathrm{~kg}$ e herdabilidade de 0,35 . Os valores da razão sexual nas populações de seleção foram de 1:50 e 1:25 (macho: fêmeas), correspondendo aos tamanhos efetivos da população de 23,53 e 57,69 animais, respectivamente. Os ganhos genéticos individuais foram maiores para a seleção baseada no BLUP, atribuídos à sua mais alta acurácia na predição dos valores genéticos. Considerando-se cada método de seleção, não houve diferenças significativas entre os dois tamanhos efetivos quanto aos valores fenotípicos médios por geração. A endogamia média aumentou em ambos os métodos de seleção e tamanhos efetivos. Maior aumento e oscilação nos valores ocorreram para a seleção baseada no BLUP no menor tamanho. Embora a seleção tenha sido realizada por pequeno número de gerações, os resultados permitiam discriminar as combinações que proporcionaram maior incremento de endogamia.
\end{abstract}

Palavras-chave: bovino, simulação em computador, ganho genético, endogamia, método de seleção

\begin{abstract}
The program GENESYS was utilized to simulate herds of beef cattle selected, for five generations, by individual selection or selection based on best linear unbiased prediction (BLUP). Average phenotypic values and inbreeding average of simulated animals from these methods were compared. The simulated quantitative trait was daily weight gain with average initial phenotypic value of $1 \mathrm{~kg}$ and heritability of .35. The values of sexual ratio in the selection populations were 1:50 and 1:25 (male: females), corresponding to effective population sizes of 23.53 and 57.69 animals, respectively. The individual genetic gains were larger for animals under BLUP selection as a result of higher accuracy of the predicted genetic values. No significant difference between the effective population sizes for average phenotypic values by generation within each selection method was found. The inbreeding coefficient increased within both selection methods and effective sizes. Larger increase and oscillation were observed for selection based on BLUP in the population with smaller effective size. Although a short term selection program was simulated, the results allowed to discriminate combinations which resulted in larger inbreeding increment.
\end{abstract}

Keywords: bovine, computer simulation, genetic gain, inbreeding, selection method

Recebido em 8 de setembro de 2004

Aceito em 25 de agosto de 2005

E-mail: eliz.cunha@bol.com.br

Apoio: $\mathrm{CNPq}$ 


\section{INTRODUÇÃO}

A pecuária bovina de corte brasileira vem exibindo índices de desenvolvimento incontestáveis, respondendo, na balança comercial, por parcela significativa da receita creditada ao agronegócio. Este aspecto justifica a implementação de programas de avaliação genética aplicados às diferentes raças, no intuito de fornecer informações mais precisas e indispensáveis ao crescimento desse setor produtivo.

Segundo Faria (2002), um dos principais grupamentos zebuínos é representado pela raça Nelore. Introduzida no Brasil a partir do século XIX, é a raça mais numerosa, destacando-se no cenário nacional pela sua utilização quase que exclusiva para a produção de carne.

Para viabilizar os programas de melhoramento genético, torna-se necessário conhecer os diferentes fatores que potencialmente interferem no processo seletivo. O tamanho efetivo da população é um dos que chamam a atenção, pois seu decréscimo pode estar associado ao aumento do nível de endogamia. Isso ocorre principalmente em razão do uso intensivo de alguns poucos touros melhoradores nos rebanhos e do aumento observado da variância do número de progênies por reprodutor em gerações sucessivas.

Endogamia alta implica redução da variabilidade genética, o que afeta as características relacionadas à reprodução e ao valor adaptativo dos animais, e a expectativa de se obter resposta futura à seleção. Goddard e Smith (1990) sugeriram tamanho efetivo mínimo de 40 animais por geração no intuito de maximizar o retorno econômico. Para Meuwissen e Woollians (1994), valores do tamanho efetivo entre 31 e 250 animais preveniriam decréscimos no valor de adaptação.

Considerando um ciclo reprodutivo médio de bovinos de corte em torno de três a quatro anos, o esforço demandado na condução dos programas de melhoramento dessa espécie pode estender-se por algumas décadas, dependendo do número de gerações que se pretende avaliar. Nesse sentido, o uso de dados simulados permite conduzir a seleção por gerações necessárias para avaliar o comportamento dos diferentes parâmetros e, dessa forma, extrapolar os resultados para as populações reais.

Este estudo teve por objetivo avaliar os ganhos genéticos, traduzidos em valores fenotípicos médios, e a endogamia média em dois tamanhos efetivos de rebanhos de gado de corte, submetidos à seleção individual e baseada no BLUP, durante cinco gerações.

\section{MATERIAL E MÉTODOS}

Para simular estruturas de rebanhos semelhantes àquelas observadas em gado de corte, foi utilizado o programa GENESYS (Euclydes, 1996), escrito para o compilador FORTRAN. O genoma simulado tinha 29 pares de cromossomos autossômicos, cujos tamanhos variavam entre si em $12 \%$, sendo aleatoriamente distribuídos por um comprimento total de $3.000 \mathrm{cM}$. Por todo o genoma foram alocados, ao acaso, 200 locos quantitativos dialélicos simulados, seguindo distribuição uniforme, com valor inicial médio de 0,50. Assumiu-se distribuição normal para os efeitos aditivos dos genes, cujas freqüências iniciais eram iguais em ambos os sexos, não sendo permitidas interações entre eles. Foram simulados três efeitos fixos com 20, 10 e quatro classes, representando rebanho-ano-estação, nessa ordem. Os efeitos de ambiente seguiram distribuição normal e foram simulados com variância que resultasse no valor de herdabilidade igual a 0,35 para a característica hipotética ganho de peso diário, selecionada no sentido de aumento nos seus valores. Para essa característica, admitiram-se valor fenotípico médio inicial de $1 \mathrm{~kg}$ e variância genética média de 30.000. Nessa etapa, o simulador recebeu o comando para efetuar 250 rotações de ajuste com diferença mínima de $2 \%$.

A população-base simulada foi constituída de 1.000 indivíduos, 500 machos e 500 fêmeas, não aparentados.

Para fins de simulação, a população inicial, gerada a partir da anterior, originou-se da escolha e acasalamento ao acaso de 15 reprodutores com 20 fêmeas cada um, ou seja, 300 fêmeas, produzindo cinco filhos por fêmea por reprodutor, totalizando 1.500 animais. Nessa fase, iniciaram-se os laços de parentesco entre os indivíduos, pois na formação dos seus gametas 
ocorreram processos como o pareamento dos cromossomos, com ou sem permutação de fragmentos, contendo um ou mais genes, à semelhança do que ocorre nas populações reais.

Os animais dessa população inicial foram progenitores daqueles das populações selecionadas, que foram avaliados quanto aos valores fenotípicos médios e endogamia média, aplicando-se a seleção individual e a seleção baseada no BLUP, por meio da metodologia de modelos mistos, com uso do modelo animal. No modelo estatístico foram considerados todos os efeitos fixos simulados e os efeitos aleatórios de animal e de ambiente.

Os tamanhos efetivos das populações de seleção foram de 23,53 e 57,69, correspondendo aos valores da razão sexual de 1:50 e 1:25 (macho: fêmeas), respectivamente, calculados com base na fórmula de Wright (1931), citado por Falconer (1987): $1 / \mathrm{N}_{\mathrm{e}}=1 / 4 \mathrm{~N}_{\mathrm{m}}+1 / 4 \mathrm{~N}_{\mathrm{f}}$. Foram admitidos para a primeira razão sexual a seleção com o acasalamento ao acaso de seis machos e 300 fêmeas, produzindo quatro progênies por acasalamento, num total de 1.200 animais por geração. Para a segunda razão, esses valores foram de 15 machos e 375 fêmeas, produzindo quatro progênies por acasalamento, num total de 1.500 animais por geração.

Os rebanhos assim formados foram submetidos à seleção por cinco gerações consecutivas e discretas, sendo todo o processo repetido por 25 vezes ou ciclos, começados sempre na mesma população inicial, com o objetivo de reduzir os efeitos da oscilação genética.

\section{RESULTADOS E DISCUSSÃO}

Constataram-se aumentos nos ganhos genéticos, no decorrer das gerações, para ambos os métodos de seleção e tamanhos efetivos da população. Valores de magnitude mais alta foram observados para a seleção com base no BLUP, sobretudo no maior tamanho efetivo da população, em relação à seleção individual. De acordo com Wei et al. (1996), esses métodos diferem na acurácia com que os valores genéticos individuais são preditos. No curto prazo, a maior acurácia da metodologia BLUP otimiza a resposta à seleção, especialmente para características de baixa herdabilidade, em função de usar todas as informações disponíveis dos parentes na obtenção da matriz dos numeradores do coeficiente de parentesco de Wright.

Entretanto, considerando-se cada método de seleção (Fig. 1, 2, 3, 4 e 5), não se observaram diferenças significativas nos valores fenotípicos médios para os dois tamanhos efetivos $(23,53 \mathrm{e}$ 57,69). Ressalta-se, contudo, que valores médios de magnitude mais elevada (Fig. 1, 2 e 3) e com maior oscilação (Fig. 4 e 5) foram observados para o menor dos tamanhos efetivos avaliados, que corresponde a uma intensidade de seleção mais alta aplicada aos rebanhos. Essa constatação foi mais evidente para a seleção individual, na qual, em todas as gerações, o fenótipo médio para o ganho de peso foi superior no menor tamanho efetivo $(23,53)$. Por ser um método que não faz uso das informações de parentesco, resulta em menores endogamia e acúmulo da endogamia ao longo das gerações. Nesse caso, os rebanhos ficam menos sujeitos aos efeitos prejudiciais, como redução da variabilidade genética. Para a seleção baseada no BLUP, até a terceira geração, pelo menos, a população de menor tamanho efetivo foi também a que exibiu maiores ganhos. A partir dessa geração, os efeitos negativos da elevação e acúmulo nos níveis da endogamia passaram a prevalecer em detrimento dos aspectos favoráveis da mais alta intensidade de seleção.

O fato de as populações apresentarem valores fenotípicos médios próximos sugere que, apesar de numericamente distintos, esses dois tamanhos refletem o acasalamento de um único reprodutor com um número grande de fêmeas (1:50 e 1:25, nessa ordem). Isso se traduz no uso intensivo de poucos touros com valor genético superior, acarretando aumentos nos valores da endogamia, ao longo das gerações. Goddard e Smith (1990) sugeriram tamanho efetivo mínimo de 40 animais por geração para maximizar o retorno econômico, enquanto Meuwissen e Woollians (1994) recomendaram valores entre 31 e 250 para prevenir decréscimos no valor adaptativo. 

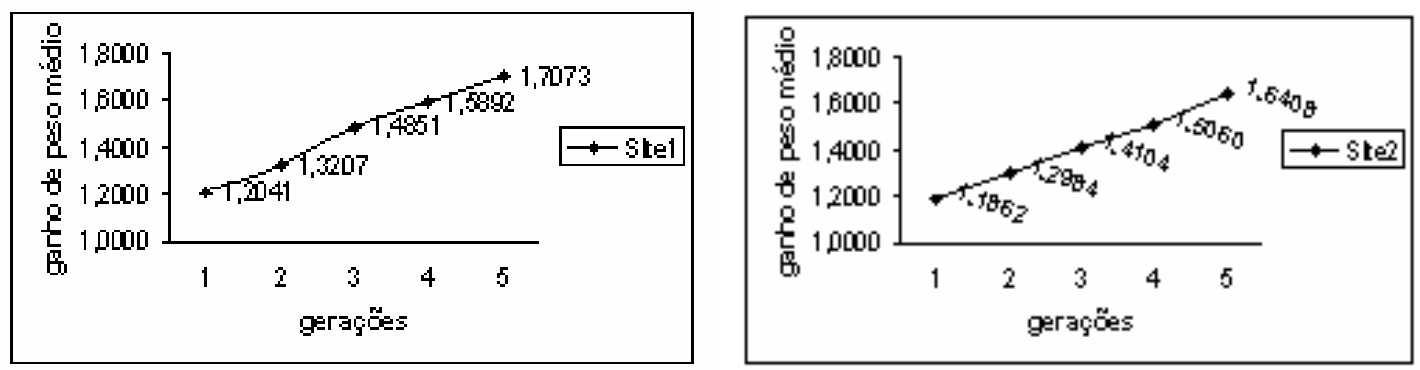

Figura 1. Ganho de peso médio por geração para populações submetidas à seleção individual, considerando os tamanhos efetivos de 23,53 (SIte1) e 57,69 (SIte2), durante cinco gerações consecutivas e discretas.
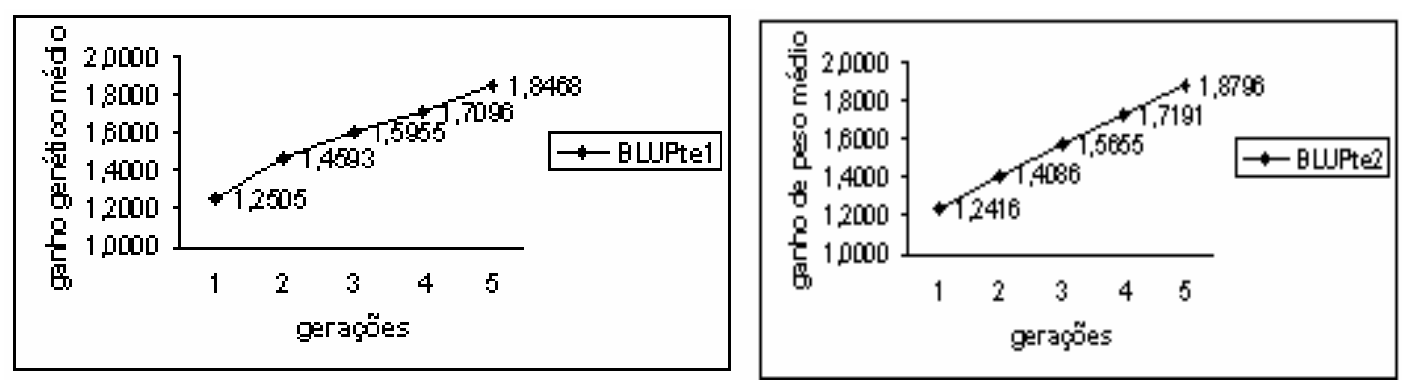

Figura 2. Ganho de peso médio por geração para populações submetidas à seleção baseada no BLUP, considerando os tamanhos efetivos de 23,53 (BLUPte1) e 57,69 (BLUPte2), durante cinco gerações consecutivas e discretas.
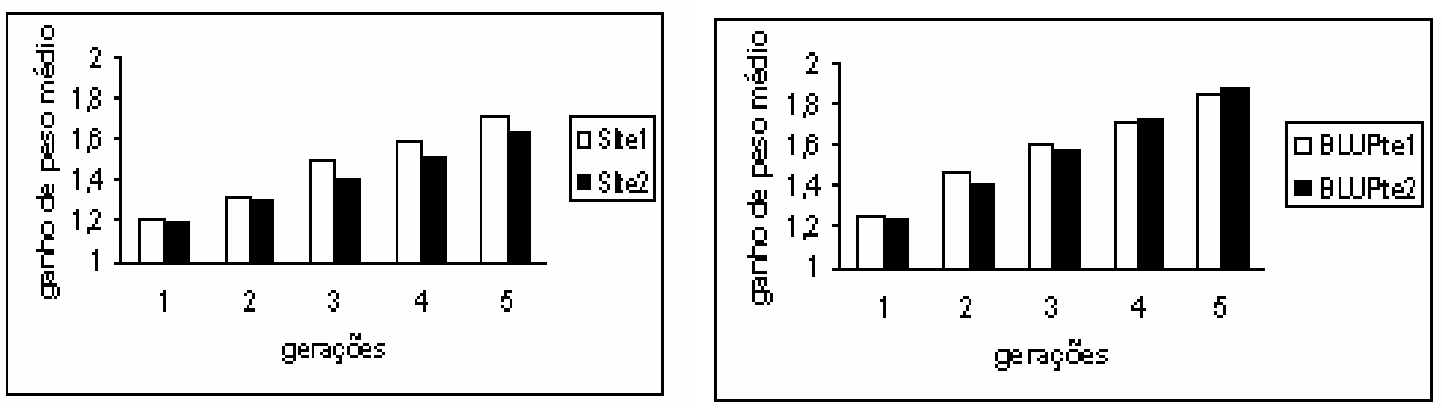

Figura 3. Comparações do ganho de peso médio por geração, nos tamanhos efetivos $1(23,53)$ e $2(57,69)$, para populações submetidas à seleção individual e à seleção baseada no BLUP.

No decurso da seleção, foram observados aumentos nos valores da endogamia média, mais intensos e oscilantes (Fig. 6, 7 e 8) para a seleção baseada no BLUP, independentemente do tamanho efetivo avaliado. Utilizando-se essa metodologia, ocorre a seleção de um número maior de indivíduos da mesma família devido à alta correlação de desempenho entre eles, ao longo das gerações. Endogamia alta, aliada a decréscimos na variância genética aditiva, compromete a expectativa de obtenção de respostas futuras à seleção, sobretudo no médio e longo prazos, ainda mais se a característica alvo da seleção apresenta um baixo valor de herdabilidade, situação em que o peso atribuído às informações da família é maior (Euclydes, 1996). Neste estudo, atribuiu-se ao ganho de peso um valor moderado de herdabilidade $(0,35)$. 

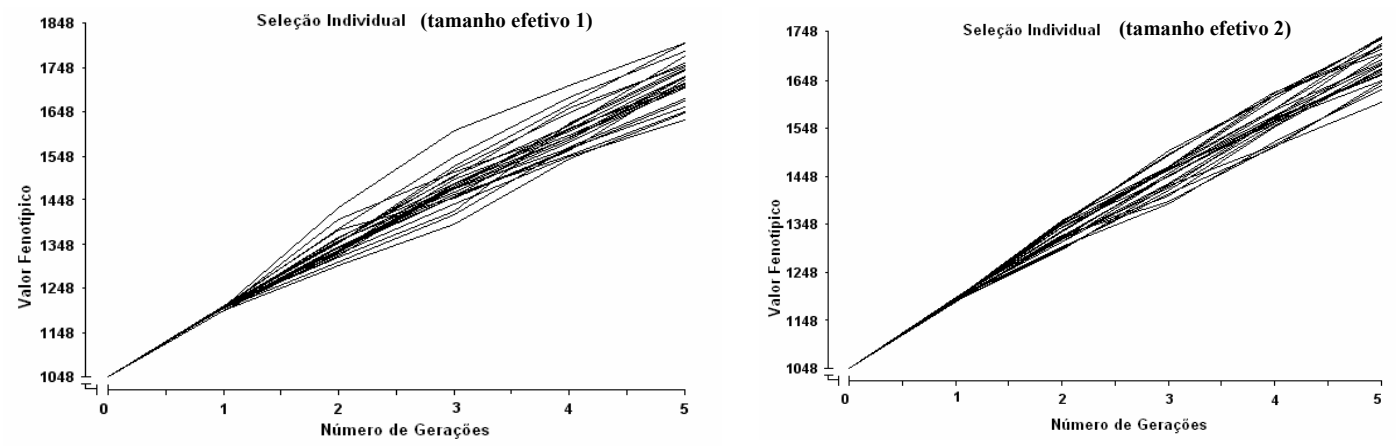

Figura 4. Oscilação dos valores fenotípicos médios por geração, considerando-se 25 ciclos, para a seleção individual nos tamanhos efetivos 1 e 2 .
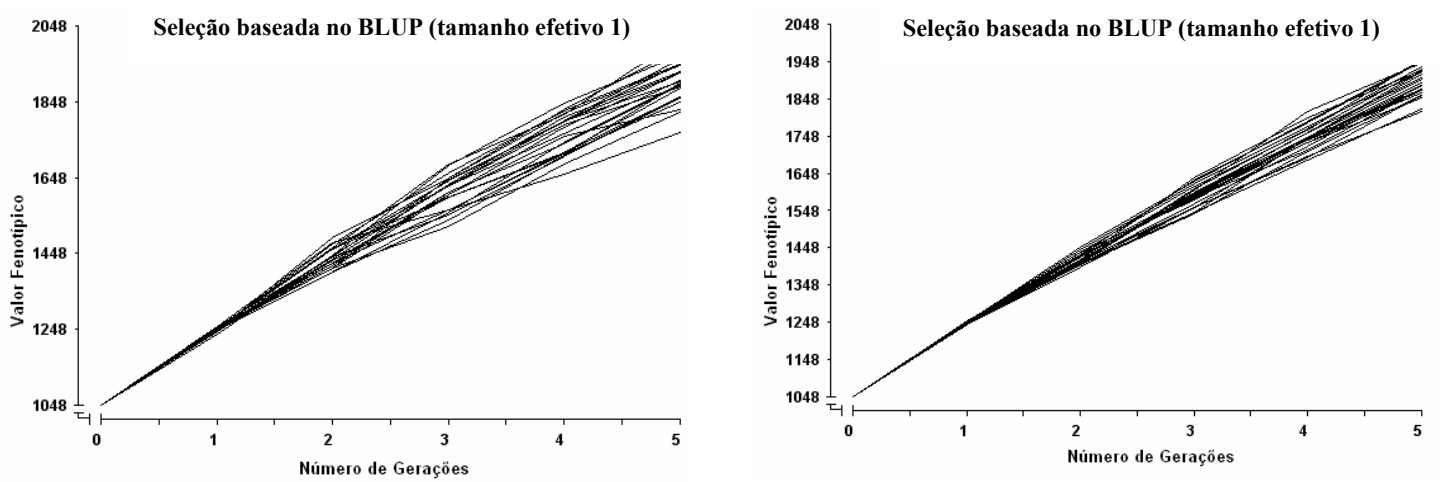

Figura 5. Oscilação dos valores fenotípicos médios por geração, considerando-se 25 ciclos, para a seleção baseada no BLUP nos tamanhos efetivos 1 e 2 .

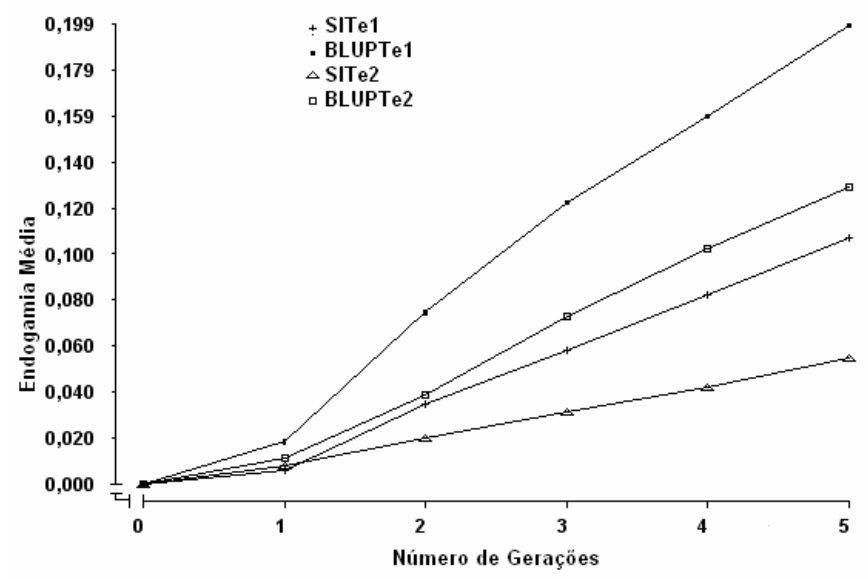

Figura 6. Valores da endogamia média ao longo de cinco gerações de seleção, considerando-se a seleção individual e a baseada no BLUP, nos dois tamanhos efetivos da população. 


\section{Cunha et al.}
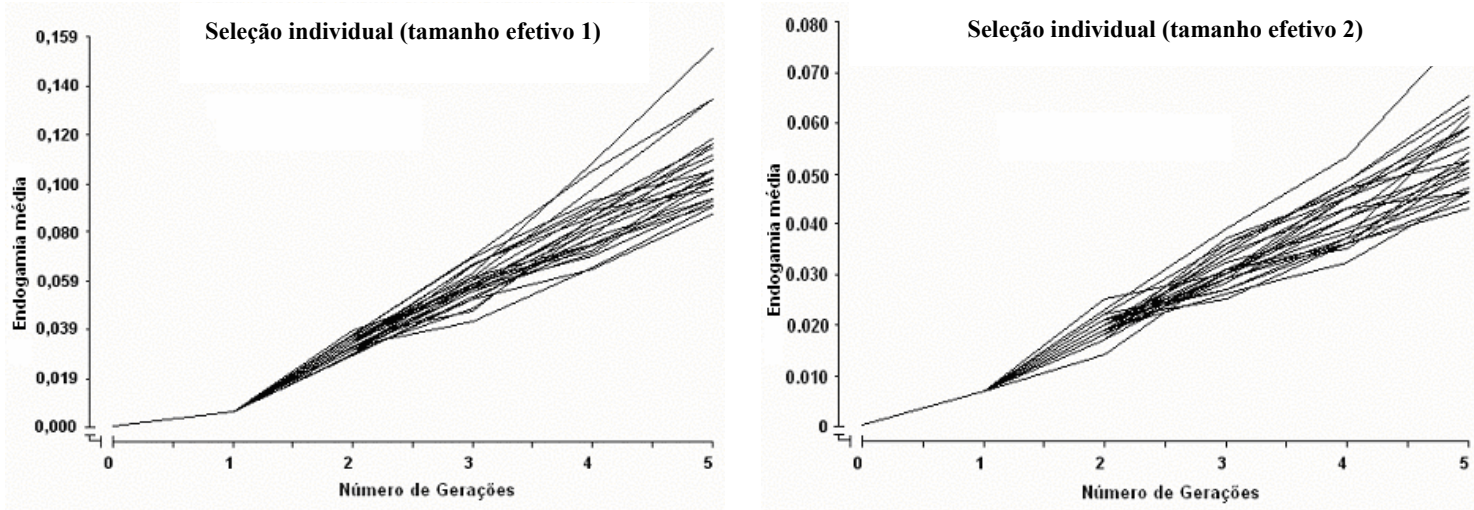

Figura 7. Oscilação dos valores da endogamia média por geração, considerando-se 25 ciclos, para a seleção individual, nos tamanhos efetivos 1 e 2 .

Em cada método de seleção, os aumentos nos valores da endogamia média foram maiores e exibiram maior oscilação no menor tamanho efetivo $(23,53)$ (Fig. 6, 7 e 8). Cunha et al. (2003), em estudos de simulação, com o objetivo de avaliar os efeitos de diferentes tipos de acasalamento, bem como os de razões sexuais sobre o controle nos níveis da endogamia média, em populações submetidas à seleção com base no BLUP, durante 50 gerações discretas, obtiveram valores mais baixos desse parâmetro nas populações de maior tamanho efetivo $(36,36)$ avaliadas.
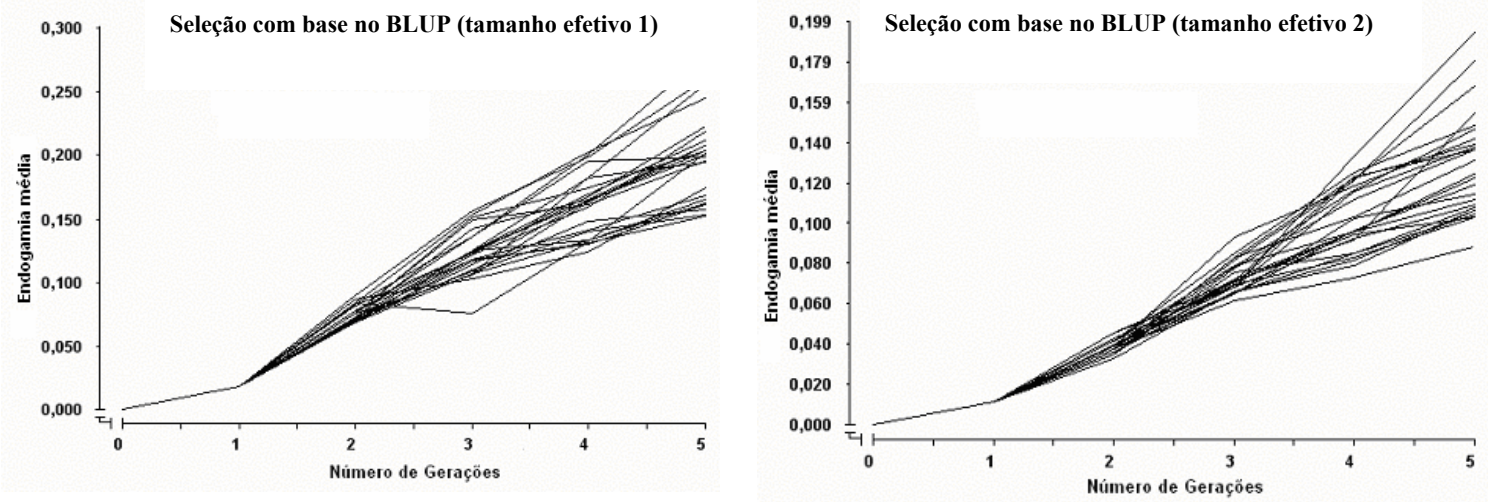

Figura 8. Oscilação dos valores da endogamia média por geração, considerando-se 25 ciclos, para a seleção baseada no BLUP, nos tamanho efetivos 1 e 2 .

Em geral, nota-se crescente preocupação com o decréscimo no tamanho efetivo da população, sobretudo nos programas de avaliação genética das diferentes raças. Faria (2002), ao estimar o tamanho efetivo para a raça Nelore, grupamento genético que possui a maior população dentre as demais raças utilizadas na pecuária de corte nacional, constatou para os períodos de 1979-83, 1984-88, 1989-93 e 1994-98 valores de $\mathrm{N}_{\mathrm{e}}$ iguais a 106, 39, 41 e 47 para a variedade Nelore Mocho, e de $\mathrm{N}_{\mathrm{e}}$ iguais a $877,162,71$ e 34 para Nelore, respectivamente. Esses valores refletem o uso intensivo de alguns poucos touros geneticamente superiores nos rebanhos 
avaliados, além da grande variação no número de progênies deixadas por reprodutor em cada rebanho.

Os tamanhos efetivos simulados foram próximos aos relatados acima para a raça Nelore, pelo menos nos dois últimos períodos, sendo que o maior deles $(57,69)$ contemplou a faixa de valores preconizada por Meuwissen e Woollians (1994). Apesar de os efeitos prejudiciais dos níveis elevados da endogamia serem mais relevantes para características de baixa $\mathrm{h}^{2}$, é conveniente seu estudo para aquelas de média $\mathrm{h}^{2}$.

Taxas de endogamia superiores a $10 \%$ podem ser perigosas, pois podem colocar em evidência alguns genes recessivos indesejáveis (Falconer, 1987). Para uma endogamia máxima igual a $10 \%$, a seleção com base no BLUP resultou neste índice após a segunda e a quarta gerações, em média, nos tamanhos efetivos de 23,53 e 57,69 (Te1 e Te2), respectivamente. Para a seleção individual, o alcance desse mesmo valor ocorreu com atraso de, pelo menos, duas gerações, em ambos os tamanhos efetivos.

\section{CONCLUSÕES}

Em rebanhos de gado de corte, é importante considerar simultaneamente o método de seleção bem como o tamanho efetivo da população, no processo seletivo. $\mathrm{O}$ método de seleção utilizado foi mais influente sobre os níveis da endogamia do que o próprio tamanho efetivo da população.

\section{REFERÊNCIAS BIBLIOGRÁFICAS}

CUNHA, E.E.; EUCLYDES, R.F.; TORRES, R.A. et al. Efeito de tipos de acasalamentos e razões sexuais na seleção baseada no BLUP. Rev. Bras. Zootec., v.32, p.1297-1303, 2003.

EUCLYDES, R.F. Uso do sistema para simulação Genesys na avaliação de métodos de seleção clássicos e associados a marcadores moleculares. 1996. 149f. Tese (Doutorado em Genética e Melhoramento) Universidade Federal de Viçosa, Viçosa, MG.

FALCONER, D.S. Introdução à genética quantitativa. Viçosa, MG: Universidade Federal de Viçosa, 1987. 279p.

FARIA, F.J.C. Estrutura genética das populações zebuinas brasileiras registradas. 2002. 177f. Tese (Doutorado em Medicina Veterinária) - Escola de Veterinária, Universidade Federal de Minas Gerais, Belo Horizonte, MG.

GODDARD, M.G.; SMITH, C. Optimum number of bull sires in dairy cattle breeding. J. Dairy Sci., v.73, p.1113-1122, 1990 .

MEUWISSEN, T.H.E.; WOOLLIANS, J.A. Effective sizes of livestock populations to prevent a decline in fitness. Theor. Appl. Genet., v.89, p.1019-1026, 1994.

WEI, M.; CABALLERO, A.; HILL, W.G. Selection response in finite populations. Genetics, v.144, p.1961-1974, 1996.

WRIGHT, S. Evolution in Mendelian populations. Genetics, v.16, p.97-159, 1931. 